\title{
A IMPORTÂNCIA DA FORMAÇÃO DO LEITOR LITERÁRIO PARA O AUMENTO DO NÚMERO DE CONSUMIDORES CULTURAIS
}

\section{ARTIGO ORIGINAL}

REIS, Marynalva Silva Abreu ${ }^{1}$

REIS, Marynalva Silva Abreu. A importância da formação do leitor literário para o aumento do número de consumidores culturais. Revista Científica Multidisciplinar Núcleo do Conhecimento. Ano 05, Ed. 03, Vol. 12, pp. 16-32. Março de 2020. ISSN: 2448-0959, Link de

acesso: https://www.nucleodoconhecimento.com.br/educacao/formacao-do-leitorliterario

\section{RESUMO}

O incentivo à leitura literária deve ser o foco de toda sociedade comprometida com a inclusão cultural e com o desenvolvimento intelectual de seus membros, visto que a leitura é o principal mecanismo para a apropriação do conhecimento e perpetuação da cultura. Iniciativas que promovam o impulsionamento das manifestações culturais são indispensáveis para a formação do sujeito, nesse sentido, destaca-se que o bemestar de uma comunidade está intrinsecamente relacionado com a democratização do acesso à leitura e aos movimentos artísticos e culturais, que são eficazes para o lazer e entretenimento, assim como também para o enriquecimento pessoal e valorização da diversidade cultural. O objetivo desse trabalho é mostrar a importância do estímulo à leitura literária dentro e fora do espaço escolar e a necessidade da intervenção de

\footnotetext{
${ }_{1}$ Professora da Educação Básica do Estado do Tocantins. Mestranda em Ciências da Educação pela Absoulute Christian University. Pós-graduada em Língua Portuguesa e Literatura, pela Faculdade de Tecnologia Equipe Darwin, em Neuropsicopedagogia e Educação Especial e Inclusiva, pela Universidade Candido Mendes e em Literatura Infanto-juvenil, pela Faculdade Única de Ipatinga, Graduada em Pedagogia, pela Faculdade da Terra de Brasília/FTB.
} 
mediadores de leitura para a formação de leitores competentes, autônomos, críticos e consumidores de cultura. Dado o exposto, tornou-se necessário abordar por meio da revisão de literatura alguns teóricos que tratam sobre o objeto de estudo dessa pesquisa. Nesse segmento, entende-se que o investimento em equipamentos, bens, serviços e produtos culturais deve ser precedido pela formação de consumidores culturais, portanto, conclui-se que é preciso ampliar os investimentos em políticas públicas de promoção da leitura literária, do livro, da literatura, da produção literária, das bibliotecas de acesso público e de formação e valorização de mediadores de leitura para expandir o número de consumidores culturais.

Palavras-chave: Mediação de leitura literária, consumo literário e cultural, Políticas públicas de fomento à leitura.

\section{INTRODUÇÃO}

O Brasil está muito aquém do ideal em Educação Básica, comparado com os países desenvolvidos, e de acordo com os dados da pesquisa realizada pelo Banco Mundial (2018), que traz à tona a realidade sobre a educação e a aprendizagem em vários países do mundo, os estudantes brasileiros levarão 260 anos para alcançar a proficiência em leitura dos países ricos.

O resultado apresentado pelo Programa Internacional de Avaliação dos Estudantes (Pisa, sigla em Inglês), edição de 2015, coloca o Brasil na 59ª posição em leitura no ranking mundial, entre 70 países analisados, e, apesar do Brasil investir em políticas educacionais e culturais, percebemos a dificuldade dos governantes estaduais e municipais em implantar os Programas e Leis Federais que determinam a democratização do direito ao acesso à cultura, ao livro, à literatura e às bibliotecas.

Outro estudo que mede os hábitos de leitura do Brasil e de mais 30 países, realizado pela Agência NOP World Culture Score Index, constata que o Brasil se encontra na $27^{a}$ posição no ranking da leitura, com um tempo médio dedicado à leitura de livros de apenas 5 horas e 12 minutos por semana. A índia e a Tailândia são os primeiros 
colocados, com média de leitura semanal de 10 horas e 42 minutos e 9 horas e 24 minutos, respectivamente.

A pesquisa Retratos da Leitura no Brasil, 4를 edição/2015, fez um levantamento sobre o índice de leitura per capita e constatou que o brasileiro lê, em média, 2,9 livros por ano, ficando muito atrás dos países desenvolvidos, que chegam a ler até 7 livros por ano, como é o caso da França. Ainda sobre a pesquisa Retratos, $30 \%$ dos brasileiros nunca comprou um livro e $44 \%$ da população não tem o hábito de ler.

Com o objetivo de apresentar propostas de intervenção para a mudança do cenário educacional e cultural brasileiro, traçamos uma interdependência entre os termos cultura e literatura, mais especificamente entre cultura e leitura literária, com o intuito de responder ao seguinte questionamento: nos interessamos por programas culturais quando temos acesso a livros literários desde a infância ou o interesse por livros literários só acontece quando acessamos previamente atividades culturais?

No tocante aos aspectos citados acima, entendemos que o acesso ao mundo literário desperta um maior interesse por equipamentos culturais, tais como: bibliotecas, cinemas, teatros, museus, etc.

Para enfatizar a importância do tema abordado neste trabalho, realizamos uma pesquisa bibliográfica com o intuito de conhecer os aspectos teóricos e conceituais referentes à leitura literária e à formação de leitores e mediadores de leitura e mencionamos alguns teóricos que se debruçam sobre esse assunto, a fim de fortalecer e embasar o nosso estudo, sendo: Castro (1992), Abramovich (1993), Anjos (2015), Rösing e Neto (2009) e Carneiro (2003).

Nesse sentido, partimos do pressuposto de que é preciso ampliar os investimentos em políticas públicas de promoção da leitura literária, do livro, da literatura, da produção literária, das bibliotecas de acesso público e de formação e valorização de mediadores de leitura para expandir o número de consumidores culturais e, consequentemente, melhorar os indicadores culturais e educacionais do Brasil. 


\section{DESENVOLVIMENTO}

É inquestionável a conexão entre os termos literatura, leitura literária, sociedade e cultura, todavia o que pretendemos com esse estudo é evidenciar que leitores literários são fortes consumidores de produtos culturais e frequentadores de espaços difusores de cultura, visto que a leitura é uma prática social que leva ao consumo de outros bens culturais.

De acordo com a Lei № 10.753, de 30 de outubro de 2003, Art. 1ํ, Inciso II, o livro é por si só "o meio principal de difusão da cultura e transmissão do conhecimento, do fomento à pesquisa social e científica, da conservação do patrimônio nacional, da transformação e aperfeiçoamento social e da melhoria da qualidade de vida".

Dessa forma, se o livro exerce a função de propagar a cultura e se cultura é definida por Fernando Azevedo (1958), como "produção, conservação e progresso dos valores intelectuais, das ideias, das ciências e das artes", não é de se estranhar que o leitor literário sinta o desejo de experienciar as variadas formas de manifestações artísticas e culturais de uma determinada sociedade.

Traçar uma associação entre literatura e cultura não é uma tarefa difícil pois, de acordo com Lima (2010, p. 01), "o que geralmente se chama de literatura estaria contido no que se entende por cultura". Reforçamos a afirmação de Lima ao tomar como base o artigo 216, do texto constitucional, que diz:

Art. 216. Constituem patrimônio cultural brasileiro os bens de natureza material e imaterial, tomados individualmente ou em conjunto, portadores de referência à identidade, à ação, à memória dos diferentes grupos formadores grupos da sociedade brasileira, nos quais se incluem:

I - as formas de expressão;

II - os modos de criar, fazer e viver;

III - as criações científicas, artísticas e tecnológicas; 
IV - as obras, objetos, documentos, edificações e demais espaços destinados às manifestações artísticos-culturais. (BRASIL, 1988, p. 112).

Sendo assim, a literatura é considerada como patrimônio cultural e divide-se em material e imaterial. É imaterial quando o sujeito ler uma obra literária, de maneira subjetiva, em que há interação entre a obra e o leitor. Quando o livro literário assume sua materialidade e se torna um objeto de consumo, a literatura é um bem material, por ser concreta e palpável. Bronckart aponta a literatura como um patrimônio de debates:

"se a literatura é verdadeiramente um patrimônio, este patrimônio é, antes de mais nada, um patrimônio de debates, de trabalho interpretativo a propósito da pessoa humana, de sua sociabilidade, da diversidade sociocultural, e das possibilidades do uso da língua". (BRONCKART op. cit., p. 17, apud COLOMER, 2007, p. 29).

Desse modo, entendemos que a literatura é uma manifestação artística indissociável de outros segmentos artísticos, tais como: teatro, dança, música, cinema, fotografia, grafite, arte circense, pintura, escultura e jogos eletrônicos e que, consequentemente, quem lê livros literários sente necessidade de consumir os demais produtos culturais, pois a leitura literária possibilita o acesso ao mundo cultural.

Como a literatura está intrinsecamente relacionada com a sociedade, existe um interesse em aproximar os estudos literários dos estudos culturais, com esse propósito a literatura tornou-se estudo das mais diversas áreas "e a ideia de seu valor como construção cultural das pessoas", defendida por Colomer (2007, p.28), foi indicada por vários autores, conforme afirma Cassarini e Fredericis:

A literatura é sentida como uma das formas em que se auto-organiza e se autorrepresenta o imaginário antropológico e cultural, um dos espaços em que as culturas se formam, se encontram com outras culturas, as absorvem, pretendem confrontar-se ou conquistá-las; ou 
bem elas desenvolvem, no seu interior, modelos alternativos aos existentes, ou criam modelos e imagens do mundo que, através da retórica da argumentação e da persuasão, tratam de impor-se aos diferentes estratos de público que configuram o tecido social. [...] a literatura oferece importantíssimos suportes e modelos para compreender e representar a vida interior, os afetos, as ideias, os ideais, as projeções fantásticas e também, modelos para representarmos nosso passado, o de nossa gente, e o dos povos, a história. (CASSARINI e FREDERICIS, 1988, p. 28, apud COLOMER, 2007, p. 29).

Se a leitura literária contribui com a formação cultural do indivíduo, não podemos considerar o ato de ler como uma atividade isolada, visto que a leitura se desenvolve em um âmbito cultural mais abrangente e, de acordo com Martins (1988, p. 10), apesar do conceito de leitura está limitado à "decifração da escrita, sua aprendizagem, no entanto, liga-se por tradição ao processo de formação global do indivíduo, à sua capacitação para o convívio e atuações social, política, econômica e cultural".

Portanto, reforçamos que a literatura além de está diretamente ligada com a vida em sociedade, contribui ainda com a promoção de mudanças sociais, conforme esclarece Silva:

A literatura está vinculada à sociedade em que se origina, assim como todo tipo de arte, pois o artista não consegue ser indiferente à realidade. A obra literária é resultado das relações dinâmicas entre escritor, público e sociedade, porque através de suas obras o artista transmite seus sentimentos e idéias do mundo, levando seu leitor à reflexão e até mesmo à mudança de posição perante a realidade, assim a literatura auxilia no processo de transformação social. (SILVA, 2019, p. 01).

Sobre esse aspecto, salientamos que a literatura tem relação com vários campos do saber, porém nos ateremos em traçar sua ligação direta com as produções artísticas e com o consumo cultural. 
A literatura propaga as manifestações culturais e a arte em todos os seus aspectos, e a construção do leitor literário em potencial contribui para a formação de consumidores culturais, devido à função social da leitura, conforme reforça Noberto:

Assim, pode-se perceber que leitura é um dos meios mais eficientes de formar cidadãos, e a literatura, parte intrínseca desta, é uma das mais belas formas da expressividade humana. Sua função social permite 0 gosto pelas artes, cultura e conhecimento de si mesmo, pois tem o poder de expressar os sentimentos mais especiais do homem, merecendo, desta forma, a importância e os valores sociais enquanto manifestação artística. (NOBERTO, 2011, p. 01).

Nessa perspectiva, como a leitura de livros literários é indispensável para a formação social e cultural do sujeito e proporciona diversidade cultural, enfatizamos que o incentivo à leitura literária, ao livro e à literatura deve ser priorizado, a fim de aumentar o número de consumidores culturais.

Nesse caso, partimos do pressuposto de que todo consumidor de livros literários é consumidor cultural, e que para ser consumidor cultural é preciso levar em consideração outro fator importantíssimo que é o acesso à escolarização, pois de acordo com os teóricos Silva, Araújo e Souza (2007, p. 106) "o direito à cultura implica também o desenvolvimento de capacidades que advêm dos processos de escolarização. Ser escolarizado é um dos traços que caracterizam o consumidor contumaz de bens culturais".

Para ampliar os nossos conhecimentos sobre a formação do leitor literário abordamos três pontos que consideramos importantes, que são: a leitura literária, as políticas públicas de fomento à leitura literária e a formação de mediadores de leitura.

O primeiro ponto considerado importante é conhecer o que é leitura literária e o que é ser leitor literário, para tanto, explicitamos que leitura literária é aquela em que o texto lido tem função estética e poética voltada para o entretenimento do leitor. São considerados textos literários os poemas, os contos, romances, novelas, fábulas, 
lendas, crônicas, peças teatrais, dentre outros. Por outro lado, os textos não literários têm função didática, sendo: artigos científicos, livros didáticos, notícias, entrevistas, dicionários, bulas de remédios, manuais de instruções, etc. Para que não fique dúvidas, consideramos leitor literário aquele que lê textos literários e leitor não literário, quem pratica a leitura somente de textos não literários.

Ressaltamos que a leitura tem uma função social imprescindível para a transmissão dos valores culturais de uma geração a outra. É indiscutível o fato de que a leitura está presente em todos os lugares que frequentamos e temos convicção de que todas as escolas enfrentam a árdua missão de incutir nos alunos o interesse pela leitura, entretanto sabemos que o público infantil mesmo tendo um interesse fulgurante pelo ato de ler e de ouvir contos e recontos de histórias infantis, quando chega na adolescência, geralmente, a leitura se torna desinteressante para grande parte desse público.

Esse tipo de desinteresse nos leva a crer que existem dois tipos de leituras: a leitura funcional e a leitura cultural. A primeira é aquela que aprendemos na escola, através da decifração do código linguístico, feita de forma mecanizada, e na maioria das vezes, é realizada por obrigação, para cumprir determinado tipo de tarefa escolar. Já a leitura cultural é aquela em que o indivíduo não apenas compreende o que lê, mas também se posiciona e interage com o texto lido. Assumção (2009, p. 56) reforça esses dois tipos de leituras ao definir leitor vital como aquele que pratica a leitura cultural e, leitor-massa, aquele que executa a leitura funcional. Ou seja, o leitor vital é aquele que, mesmo numa sociedade moderna, em meio a tantas tecnologias e equipamentos responsáveis pela distração e superficialidade de informações, consegue se envolver com a leitura de maneira autônoma e prazerosa, ao contrário do leitor-massa, que ler superficialmente, porque sua "cabeça está cheia de ideias inercialmente recebidas, heteronomamente vividas". Assumção associa o termo "leitor-massa" ao conceito de "homem-massa" dado pelo filósofo espanhol José Ortega y Gasset. Para Ortega o homem-massa é um sujeito passivo, que se acomoda facilmente e não se preocupa em transformar a realidade em que vive. De acordo com Assumção (2009, p. 47), "A leitura - e leitura no sentido amplo de ler o mundo, de ler 
imagens, de ler palavras - nos impõe a necessidade de uma relação ativa, de construção, de comprometimento e de responsabilidade com uma visão própria de mundo (autonomia)".

Para esclarecer melhor o conceito de leitor-massa, Assumção continua comparandoo com o homem-massa:

[...] o leitor-massa que ascendeu pelo alçapão da história, passou a intervir em tudo, e violentamente, em tudo e em todos os textos, no século XX. Como o homem-massa, o leitor-massa, com seus gestos e gostos, chega ao palco montado por uma ciência que ele não conhece, iluminado por uma luz que ele não inventou, mas que parece estar aí desde sempre, e, invertebrado em seus valores, passa a dar espaço ao desenvolvimento muito mais intenso e muito mais abrangente do mercado, que é quem dita, no vácuo deixado pela invertebração, o bem e o mal, o verdadeiro e o falso, o belo e o feio, também em termos de literatura. (ASSUMÇÃO, 2015, p. 58).

Para Assumção (2009, p.58), a prática leitora já não tem mais valor, "virou algo abstrato, com pouco sentido vital, incapaz de despertar qualquer desejo e formar novos leitores", e para tornar a leitura vital para a sociedade é necessária "uma reforma radical da ideia de leitura praticada na escola e na universidade".

Colomer (2007, p. 50) traça o perfil do leitor literário e classifica os tipos de leitores de acordo com a denominação usada nas pesquisas francesas, que faz a seguinte divisão: "débeis" - aqueles que leem de zero a quatro livros por ano; "médios" - os que leem de cinco a nove livros; "fortes" - aqueles que leem mais de dez livros por ano".

Conhecer o perfil do leitor é uma busca constante, todavia independentemente do leitor ser leitor-massa, leitor-débil, leitor-médio ou leitor-forte, o que de fato consideramos importante é que a leitura seja vista como necessária e indispensável para a formação plena do indivíduo, para a perpetuação da cultura de uma 
determinada sociedade e para a difusão de outras culturas. Devemos propagar o desenvolvimento de atitudes positivas em relação à leitura, pois 0 ato de ler não deve ser meramente mecânico e sem significado. E mais ainda, precisamos envolver as pessoas que são capazes de ler para que pratiquem esse ato regularmente, pois de acordo com Cramer \& Castle (2001, p. 14) a "Aliteratura, pode ser um problema maior do que o analfabetismo". Para as respectivas autoras a "Aliteratura" é a falta do hábito da leitura entre leitores que sabem ler, mas preferem não ler.

Sobre esse aspecto, reforçamos a importância da parceria entre família e escola para assegurar o desenvolvimento do hábito da leitura em crianças e adolescentes, pois de acordo com Castro (1992, p. 01), "garantir a riqueza da vivência narrativa desde os primeiros anos de vida da criança contribui para o desenvolvimento do seu pensamento lógico e também de sua imaginação".

Abramovich enfatiza a importância de ouvir histórias para a formação da criança:

Ah, como é importante para a formação de qualquer criança ouvir muitas, muitas histórias... Escutá-las é o início da aprendizagem para ser um leitor, e ser leitor é ter um caminho absolutamente infinito de descoberta e compreensão de mundo [...] é ouvindo histórias que se pode sentir (também) emoções importantes, como a tristeza, a raiva, a irritação, o bem-estar, o medo, a alegria, o pavor, a insegurança, a tranquilidade, e tantas outras mais, e viver profundamente tudo o que as narrativas provocam em quem as ouve - com toda a amplitude, significância e verdade que cada um delas fez (ou não) brotar... Pois é ouvir, sentir e enxergar com os olhos do imaginário! (ABRAMOVICH, 1993, p. 16 e 17).

Crianças que têm acesso a livros literários, seja em casa ou na escola, podem desenvolver o hábito da leitura espontaneamente, sem a ajuda de terceiros, todavia, se essas crianças além de terem acesso a livros literários, tiverem também adultos leitores como exemplos, aprenderão a gostar de ler, assim como também amarão a leitura e se tornarão leitores assíduos e contagiantes. 
Por outro lado, crianças que não têm contato algum com livros literários e não convivem com adultos que leem, terão grandes chances de se manterem afastados do mundo da leitura, reduzindo assim as possibilidades de se tornarem adultos leitores, entretanto destacamos que se tiverem acesso à literatura na fase adulta é perfeitamente possível desenvolver o gosto pela leitura retardatariamente.

Como mencionamos acima, a maneira mais eficaz de envolver crianças e conquistálas para o universo da leitura é através do exemplo, seja dos pais, de irmãos mais velhos ou de qualquer adulto que convivam em casa. Outra maneira significativa é por intermédio das atividades de leitura promovidas na escola, entretanto a escola apresenta uma questão não muito favorável que é a leitura obrigatória, atrelada à obtenção de notas e com preenchimento de fichas de leituras, que nem sempre cativam os estudantes.

Segundo Silva (2009, p. 24) "A literatura científica da área da leitura aponta para o fato de que a formação do leitor passa por diferentes etapas de desenvolvimento, envolvendo a ação de múltiplas instituições sociais: família, grupo de amigos, escola, bibliotecas [...]."

Dentre as instituições citadas por Silva, apontamos a família e a escola como as duas mais importantes, porém vale destacar que uma não exime a outra, ou seja, a missão da escola de formar leitores não isenta, tampouco substitui a participação da família, conforme afirma Antunes:

[...] essa prioridade da escola na formação do leitor não exclui, evidentemente, a atuação da família, na ação diuturna dos pais, que devem assumir a iniciação da criança nesse mundo gráfico (e, por vezes, mágico) das palavras. Não exclui ainda a sociedade, os meios de comunicação - todos: jornais, revistas, TV, páginas da internet - nem exclui (principalmente essas!) as políticas públicas orientadas para a educação e a promoção da cultura letrada (ANTUNES, 2009, p. 202). 
O poder de influência da família na formação leitora de seus membros é inquestionável. O hábito da leitura quando é adquirido no aconchego do lar estreita laços, fortalece as relações afetivas e aumenta o interesse pelo ato de ler e a possibilidade da criança se tornar um adulto leitor, e ainda:

O leitor formado na família tem um perfil um pouco diferenciado daquele outro que teve o contato com a leitura apenas ao chegar à escola. $\mathrm{O}$ leitor que se inicia no âmbito familiar demonstra mais facilidade em lidar com signos, compreende melhor o mundo no qual está inserido, além de desenvolver um senso crítico mais cedo, o que 'é' realmente importa na sociedade. (VIEIRA, 2004, p. 06, apud BOTINI e FARAGO, p.02, 2014).

Torna-se evidente que a probabilidade de um indivíduo se tornar leitor é infinitamente maior quando se tem acesso a livros literários na infância, e ainda, quando se tem contato com pessoas que leem e que favorecem o acesso à leitura. Segundo a pesquisa Retratos da Leitura no Brasil 4, as mães são as principais influenciadoras do hábito da leitura, enquanto que os professores ocupam o segundo lugar na influência do gosto pela leitura.

Por isso, a família, assim como a escola, exerce papel extremamente relevante na mediação da leitura, porém acreditamos que a família é a base de tudo, visto que se o professor não adquiriu o hábito da leitura no seio familiar, provavelmente ele terá dificuldade em incentivar os seus alunos a lerem, como afirma Lajolo (1985, apud SILVA, 2009, p. 25): "caso as relações do professor com os livros forem débeis, grandes serão as chances de que a sua atuação na esfera do ensino da leitura deixará muito a desejar."

O segundo ponto considerado importante para a formação do leitor é conhecer as políticas públicas de fomento à leitura literária, e, de acordo com os nossos estudos, o marco inicial das discussões sobre a valorização do livro e leitura aconteceu em 2003 com a promulgação da Lei 10.753, que instituiu a Política Nacional do Livro. De acordo a Lei supramenciona, o livro está diretamente ligado à cultura e colabora com a sua perpetuação, conforme citamos acima. 
As principais diretrizes da lei 10.753 reforçam que o livro e a leitura merecem lugar de destaque e o poder público deve:

I - Assegurar ao cidadão o pleno exercício do direito de acesso e uso do livro;

II $-[\ldots]$

III - fomentar e apoiar a produção, a edição, a difusão, a distribuição e a comercialização do livro;

IV - Estimular a produção intelectual dos escritores e autores brasileiros, tanto de obras científicas como culturais;

V - Promover e incentivar o hábito da leitura;

VI - Propiciar os meios para fazer do Brasil um grande centro editorial;

VII - competir no mercado internacional de livros, ampliando a exportação de livros nacionais;

VIII - apoiar a livre circulação do livro no País;

IX - Capacitar a população para o uso do livro como fator fundamental para seu progresso econômico, político, social e promover a justa distribuição do saber e da renda;

X - Instalar e ampliar no País livrarias, bibliotecas e pontos de venda de livro;

XI - propiciar aos autores, editores, distribuidores e livreiros as condições necessárias ao cumprimento do disposto nesta Lei;

XII - assegurar às pessoas com deficiência visual o acesso à leitura. (BRASIL, 2003, p. 01). 
Para promover o livro, a leitura, a escrita, a literatura e as bibliotecas públicas em 12 de julho de 2018 foi publicada no Diário Oficial da União a Lei ㄲo 13.696, que estabelece a Política Nacional de Leitura e Escrita/PNLE, com objetivos que reforçam a relevância das políticas públicas para esse setor e para a formação de mediadores de leitura, especificados em seu Artigo 3ํㅡㄹ incisos I, II e III:

I - Democratizar o acesso ao livro e aos diversos suportes à leitura por meio de bibliotecas de acesso público, entre outros espaços de incentivo à leitura, de forma a ampliar os acervos físicos e digitais e as condições de acessibilidade;

II - Fomentar a formação de mediadores de leitura e fortalecer ações de estímulo à leitura, por meio da formação continuada em práticas de leitura para professores, bibliotecários e agentes de leitura, entre outros agentes educativos, culturais e sociais;

III - Valorizar a leitura e o incremento de seu valor simbólico e institucional por meio de campanhas, premiações e eventos de difusão cultural do livro, da leitura, da literatura e das bibliotecas. (BRASIL, 2018, p. 02).

A orientação dada pela Lei o 13.696 é que o processo de democratização da leitura seja impulsionado pela União, através do Ministério da Cultura e do Ministério da Educação, em colaboração com os Estados, o Distrito Federal e os Municípios e com a contribuição da sociedade civil e das instituições privadas, entretanto acentuamos que, para garantir a implantação das leis e programas federais nas esferas estaduais e municipais, o Governo Federal deve investir no monitoramento de todas as etapas de implantação desses programas, com acompanhamento contínuo para assegurar o cumprimento das leis que regem sobre o livro, especialmente no que diz respeito à criação dos planos estaduais e municipais do livro e da leitura.

O terceiro e último ponto relevante para a formação do leitor é a formação de mediadores de leitura e como já mencionamos acima, é de notório saber que os pais 
ou responsáveis representam expressivo papel na vida das crianças em relação ao incentivo à leitura, entretanto quando não há esse estímulo na infância, a criança é capaz de desenvolver o gosto pela leitura em outro momento de sua vida? Para responder a essa pergunta tratamos sobre a importante figura do mediador de leitura, pois, "apenas circular em meio a materiais diversificados de leitura não desenvolve o gosto pelo ato de ler. É imprescindível conviver com uma ou mais pessoas que se envolvam eventual ou permanentemente com esses materiais, significando-os". (SANTOS, NETO e RÖSING, 2009, p. 13).

Nesse segmento, se para desenvolver o gosto pela leitura é preciso a intervenção de mediadores, consideramos essencial que a formação de leitores seja prioridade máxima, tanto das famílias, como das escolas e das Instituições Sociais. Essas entidades devem se envolver com a democratização da leitura, tendo em vista que a transformação de uma comunidade não leitora em leitora trará resultados positivos e, consequentemente, contribuirá para a formação de uma sociedade mais justa e igualitária.

Sugerimos como estratégia para aumentar o número de leitores a disponibilização de ambientes favoráveis ao desenvolvimento da leitura, acessíveis a todos, independentemente da classe social ou idade.

$O$ ato de ler quando não é estimulado através do exemplo, deve ser incentivado com atividades mediadoras alicerçadas em acervos literários, e, para isso, contamos com a importante participação de mediadores de leitura, conhecidos também como agentes de leitura.

Consideramos fundamental o papel do mediador de leitura, pois o mediador introduz a "dimensão cultural, hermenêutica da leitura, como complemento à leitura instrumental utilitária, pragmática, que só pode ocorrer a partir de uma nova ideia de razão, mais plenária, e de uma ilustração vital". (ASSUMÇÃO, 2009, p. 58). 
Em linhas gerais, objetivamos elencar a importância do mediador de leitura para a formação de leitores, para tanto, destacamos as características fundamentais para ser um mediador de leitura:

Para ser um agente de leitura a pessoa tem primeiro que gostar de ler, ter vontade e compromisso social de compartilhar esse gosto e sua experiência de leitura com um outro tanto de gente, formando leitores em ambientes diversos como bibliotecas públicas municipais, escolas, fábricas, empresas, associações, comunidades e dentro das casas, no seio de famílias que abrem portas para que os livros e leitura possam entrar em suas vidas." (SANTOS, 2009, p. 40 e 41).

Dessa forma, ser leitor antecede o ato de ser mediador de leitura. Essa proposição é tão evidente ao partimos da premissa de que não se ensina aquilo que não se sabe, entretanto, salientamos que é possível formar mediadores de leitura dentre pessoas que não desenvolveram o hábito da leitura literária em tempo hábil, com essa finalidade existem programas de formação continuada capazes de transformar não leitores literários em agentes/mediadores de leitura.

Com o intuito de colaborar com discussões acerca dessa temática, apresentamos abaixo os seis pontos principais que devem ser levados em consideração nas políticas para a formação de mediadores de leitura, de acordo com Neto:

1. Formar mediadores de leitura é prioridade; 2. Há locais e instituições fundamentais para a atuação de mediadores, mas eles devem estar em todos os lugares; 3. Não é vergonha ou subordinação intelectual repetir práticas simples e óbvias; 4. Em qualquer programa de formação de mediadores é importante dedicar a maior parte do tempo à leitura; 5 . Os programas de formação de mediadores do sistema público devem ser integrados às iniciativas do terceiro setor e do setor privado; 6 . Os programas de formação de mediadores de leitura são para todos. (NETO, 2009, p. 66 a 69). 
Dos seis pontos citados acima, consideramos como primordial para os programas destinados à capacitação de mediadores de leitura, o investimento no tempo dedicado à leitura. Se os programas destinados à capacitação de mediadores de leitura incluírem em suas pautas a leitura dos mais variados tipos de textos literários, mesmo que o futuro agente/mediador de leitura não tenha tido acesso prévio a esses materiais, é perfeitamente possível despertar o interesse pela leitura literária após o contato com esses textos.

Enfatizamos que o agente/mediador de leitura não precisa ter adquirido o hábito da leitura na infância ou adolescência e, ao mesmo tempo, reforçamos que a partir do momento em que ele decide ser um mediador de leitura, esse contato com textos literários é necessário, uma vez que, para o agente influenciar o seu público a desenvolver o gosto pela leitura ele precisa, além de conhecer o acervo bibliográfico, gostar de ler, trocar experiências de leituras e ter compromisso social.

Visando explicitar melhor as atribuições da função do agente/mediador de Leitura buscamos alguns teóricos que tratam sobre essa temática. Para Santos (2009, p. 45) a leitura é uma ação cultural dinâmica e o papel do agente de leitura é "despertar o interesse e o gosto pela leitura de maneira crítica e inventiva, como um prazer infinito na vida de cada pessoa" e não trabalhar a leitura meramente funcional ou instrumental.

Para alcançar êxito o agente/mediador de leitura deve estabelecer a interação do sujeito com o mundo cultural que o cerca. Santos equipara os agentes de leitura aos agentes de cultura ao declarar que:

A proposta dos Agentes de Cultura consiste em movimentar relações sociais através de instrumentos e linguagens artísticas e culturais. $\mathrm{O}$ agente é aquele que estabelece pontes de comunicação entre os universos que percorre, enfocando esses atores sociais como sujeitos que transitam entre múltiplos polos, mobilizando ideias, estilos de vida, práticas sociais, modos de percepção, objetos, linguagens e universos culturais. Dessa forma, os agentes de cultura - enfatizando aqui os 
agentes de leitura - não apenas dão movimento a esse trânsito como desempenham o papel de fazer interagir diferentes mundos $e$ experiências por meio da literatura numa interface com outras linguagens artísticas e suportes de leituras. (SANTOS, 2009, p. 39).

Sobre esse aspecto, Santos (2009, p. 38) afirma ainda que o agente de leitura deve agir na perspectiva de priorizar o acesso ao livro e a formação leitora como um "direito básico de cidadania, de inclusão social e de desenvolvimento". "Sua ação cultural é, por excelência, uma ação social de transformação da realidade onde ele está inserido. Numa dimensão mais ampla, todo agente de leitura é um agente cultural e social".

Em síntese, consideramos que se a leitura literária contribui para o aumento do número de consumidores culturais, torna-se evidente a necessidade de investir em políticas públicas para a democratização do acesso ao livro literário, com ações abrangentes capazes de inserir todas as comunidades, sejam urbanas ou rurais, no mundo da literatura.

\section{CONSIDERAÇÕES FINAIS}

Como se pode observar, iniciamos esse estudo apresentando a situação atual da educação brasileira apontada pelas avaliações externas nacionais e internacionais e ao analisarmos que o percentual de analfabetismo funcional no Brasil é de $29 \%$, não podemos esquecer que dentro desse grupo de analfabetos funcionais estão incluídos os analfabetos absolutos (quem não consegue ler palavras e frases), as pessoas com ensino médio completo e até mesmo pessoas com nível superior, ou seja, a qualidade da educação básica brasileira precisa ser alterada e o que pretendíamos ao construir esse trabalho era apontar duas alternativas para melhorar os indicadores educacionais, sendo: a democratização do acesso a livros literários e a oferta de produtos e serviços culturais.

Com a finalidade de mostrar que existe uma relação natural entre o acesso a livros literários e o interesse por equipamentos culturais, buscamos traçar uma associação entre literatura, leitura literária, sociedade e cultura, entretanto os estudos acerca 
dessa temática ainda são escassos, portanto, entendemos que os dados adquiridos através dessa pesquisa apesar de serem relevantes não são suficientes para comprovar que existe uma relação entre o acesso a livros literários e a disposição para a prática do consumo cultural, entretanto, salientamos que há possibilidade de avanço nas discussões acerca desse assunto e deixamos como contribuição a proposta de elaboração de uma pesquisa específica para estudar, durante um determinado período, os grupos de leitores e de não leitores de uma determinada comunidade e comparar o consumo cultural desses dois públicos.

\section{REFERÊNCIAS}

ABRAMOVICH, Fanny. Literatura Infantil: gostosuras e bobices. São Paulo: Scipione, 1993.

AÇÃO EDUCATIVA; INSTITUTO PAULO MONTENEGRO. INAF BRASIL 2018: Resultados preliminares. Inaf - Indicador de Alfabetismo Funcional. [documento eletrônico] disponível em: http://acaoeducativa.org.br/wpcontent/uploads/2018/08/Inaf2018_Relat\%C3\%B3rio-Resultados-

Preliminares_v08Ago2018.pdf

ANJOS, Valéria Maria Sant'Ana Britto dos Ênfase à leitura literária na escola: um caminho para formação do leitor crítico / Santo Antônio de Jesus, 2015, p.17, disponível em: http://www.profletrasdch5.uneb.br/imagens_sys/VALERIA_ANJOS.pdf.

ANJOS, Valéria Maria Sant'Ana Britto dos Ênfase à leitura literária na escola: um caminho para formação do leitor crítico / Valeria Maria Sant'Ana Britto dos Anjos. Santo Antônio de Jesus, 2015.

ANTUNES, Irandé. Língua, texto e ensino: outra escola possível. São Paulo: Parábola Editorial, 2009.

ANTUNES, W. A. Bibliotecas escolares: curso de Capacitação do professor regente de biblioteca. Brasília: CORBI, 1993. 
AZEVEDO, F. A Cultura Brasileira. Tomo I. 3ª Ed. SP: Edições Melhoramentos, 1958.

BOTINI, C.A.L; FARAGO, A.C. Formação do leitor: papel da família e da escola. Cadernos de Educação: Ensino e Sociedade, Bebedouro-SP, 1 (1): 44-57, 2014

BRASIL. Constituição (1988). Constituição da República Federativa do Brasil: promulgada em 5 de outubro de 1988. 33. Ed. Atualizada e ampliada. São Paulo: Saraiva, 2004.

BRASIL. IBGE. Censo Demográfico, 2000. Disponível em: https://cidades.ibge.gov.br/brasil/to/tocantinopolis/panorama.

BRASIL. IBGE. Panorama nacional e internacional da produção de indicadores sociais: estatísticas de governança/Leonardo Athias, Luanda Botelho, organizadores. - Rio de Janeiro: IBGE, 2019.

BRASIL. IBGE. Sistema de Informação e Indicadores Culturais. Informação demográfica e socioeconômica ํㅜㄴ 31. 2007 - 2010.

BRASIL. IBGE. Perfil dos estados e dos municípios brasileiros: cultura 2014. Rio de Janeiro, 2015.

BRASIL. LEI № 13.696, DE 12 DE JULHO DE 2018. Plano Nacional de Leitura e Escrita - Publicação Original, disponível em: http://www2.camara.leg.br/legin/fed/lei/2018/lei-13696-12-julho-2018-786975publicacaooriginal-156036-pl.html.

BRASIL. LDB: Lei de diretrizes e bases da educação nacional. - Brasília: Senado Federal, Coordenação de Edições Técnicas, 2017.

BRASIL. LEI No 10.753, DE 30 DE OUTUBRO DE 2003, disponível em: http://www.planalto.gov.br/Ccivil_03/leis/2003/L10.753.htm. 
BRASIL. PISA 2015: análises e reflexões sobre o desempenho dos estudantes brasileiros / OCDE-Organização para a Cooperação e Desenvolvimento Econômico. — São Paulo: Fundação Santillana, 2016.

BRASIL. Secretaria de Educação Fundamental. Parâmetros Curriculares Nacionais: terceiro e quarto ciclos do ensino fundamental: Introdução aos Parâmetros Curriculares Nacionais / Secretaria de Educação Fundamental. - Brasília: MEC/SEF, 1998.

BRASIL. Secretaria de Educação Fundamental. Parâmetros Curriculares Nacionais: Língua Portuguesa / Secretaria de Educação Fundamental. - Brasília, 1997.

CAFARDO, Renata, O Estadão de São Paulo, Brasil, disponível em https://educacao.estadao.com.br/noticias/geral,pais-so-deve-dominar-leitura-em-260anos,70002206631, acesso em: 05 mar. 2018, 19:30:25.

CALABRE, LIA... [et al]. Seminário Internacional Políticas Culturais (7.: 2016: Rio de Janeiro, RJ). Anais do VII Seminário Internacional de Políticas Culturais, 17 a 20 de maio de 2016. Fundação Casa de Rui Barbosa.

CANDIDO, Antonio. Literatura e Sociedade: Estudos de Teoria e História Literária. 10a. edição revista pelo autor | Rio de Janeiro: Ouro Sobre Azul 2008 | 204 pág.

CANDIDO, Antônio. Vários escritos. $3^{\mathrm{a}}$ ed. Revista e ampliada. São Paulo: Duas Cidades, 1995.

CASTRO, Eline Fernandes. A importância da leitura infantil para o desenvolvimento da criança. Artigo publicado em: http://meuartigo.brasilescola.uol.com.br/educacao/aimportancia-literatura-infantil-para-desenvolvimento.htm.

COLOMER, Teresa. A Formação do Leitor Literário; [tradução Laura Sandroni]. - São Paulo: Global, 2007.

COLOMER, Teresa. Andar entre livros: a leitura literária na escola; [tradução Laura Sandroni]. - São Paulo: Global, 2007. 
CRAMER, E. H; CASTLE, M. (organizadores). Incentivando o amor pela leitura. Porto Alegre: Artmed, 2001.

FAILLA, Zoara. Retratos da leitura no Brasil 4. Rio de Janeiro: Sextante, 2016.

FONSECA, Edson. A biblioteca escolar e a crise da educação. São Paulo: Pioneira, 1983.

FREIRE, Paulo. A importância do Ato de Ler: em três artigos que se completam. - 51 . Ed. - São Paulo: cortez, 2011. - (Coleção questões da nossa época; v. 22).

GALVÃO, Ana Maria de Oliveira. Leitura: algo que se transmite entre gerações? In: RIBEIRO, Vera Masagão (Org.). Letramento no Brasil: reflexões a partir no INAF 2001. São Paulo: Ação Educativa; Global; Instituto Paulo Montenegro, 2003. P. 125-153.

JUNIOR, Luiz Costa Pereira. Cultura Brasileira - Aula 1. Quem é brasileiro, cultura? disponível em: https://www.youtube.com/watch?v=gm4Bx2XjxYs.

JUNIOR, Luiz Costa Pereira. Cultura Brasileira - Aula 2 - A língua da cultura brasileira, disponível em: https://www.youtube.com/watch?v=TNXKOhHFQgM.

KLÉBIS, Carlos Eduardo de Oliveira. Leitura e envolvimento: a escola, a biblioteca e o professor na construção das relações entre leitores e livros. - Campinas, SP: [s.n.], 2006.

KRUG, Flavia Susana. A importância da leitura na formação do leitor. Revista de educação do IDEAU. Vol. 10, n. 22, p. 1-14, Jul./ Dez. 2015.

LEIVA, JOÃO. Cultura nas capitais: como 33 milhões de brasileiros consomem diversão e arte. Pesquisa de campo Instituto Datafolha; pesquisa e produção J. Leiva Cultura \& Esporte. - $1^{\underline{a}}$ ed. - Rio de Janeiro: 17Street Produção Editorial, 2018.

LIMA, Rachel $\quad$ Esteves. Literatura e Cultura. http://observatoriodacritica.com.br/arquivos/publicacoes/rachellima/Literatura\%20e\% 20Cultura.pdf 
MARTINS. Maria Helena. O que é leitura. 9a edição, 1988, editora brasiliense. Disponível em: file://D:/Marynalva/Downloads/O\%20QUE\%20\%C3\%89\%20LEITURA.pdf

MOTTA-ROTH, Désirée - HENDGES, Graciela H. Produção Textual na Universidade. São Paulo: Parábola Editorial, 2010.

NOBERTO, Sandra Carla. A literatura e sua importância para a sociedade. Disponível em: $\quad$ http://interativoprata.blogspot.com/2011/11/literatura-e-sua-importanciapara.html?m=1

NUNES, T.; BUARQUE, L.; BRYANT, P. Dificuldades na aprendizagem da leitura: Teoria e Prática, 7. ed. - São Paulo: Cortez, 2011. Coleção questões da nossa época; v. 33).

PENNAC, Daniel. Como um romance. Tradução de Leny Werneck. - Porto Alegre, RS: L\&PM; Rio de Janeiro: Rocco, 2011. 152p. - (Coleção L\&PM POCKET; 722).

PEREIRA, E. J.; FRAZÃO, G. C.; SANTOS, L. C. Leitura Infantil: O valor da leitura para a formação de futuros leitores. Artigo publicado em: http://portaldeperiodicos.eci.ufmg.br/index.php/moci/article/viewFile/2162/135.

PERROTTI, Edmir. Confinamento Cultural, infância e leitura. - São Paulo: Summus, 1990. - (Novas buscas em educação; v. 38).

PETIT, Michèle. Os Jovens e a Leitura: uma nova perspectiva; tradução de Celina Olga de Souza - São Paulo: Editora 34, 2009 (2ª edição).

RITER, Caio. A formação do leitor literário em casa e na escola. São Paulo. Biruta. 2009.

SANTOS, F. DOS; NETO, J.C.M; RÖSING, T.M.K (organizadores). Mediação de Leitura: discussões e alternativas para a formação de leitores. - 1. Ed. - São Paulo: Global, 2009. 
SANTZANNA, Affonso Romano... [et al] Mediação de Leitura. Discussões e Alternativas para a formação de Leitores. Global Editora, 2009.

SILVA, Cintia Maria da; BELTRAME, Renan Ribeiro. Mediação Cultural: $\begin{array}{llllll}\text { Problematizações } & \text { e } & \text { Contexto. } & \text { Anais } & \text { p. }\end{array}$ http://culturadigital.br/politicaculturalcasaderuibarbosa/files/2016/06/Anais-do-VIISemin\%C3\%A1rio-Int-Pol-Cult.pdf

SILVA, Ezequiel T. Leitura e realidade brasileira. 3. ed. Porto Alegre: Mercado aberto, 1986.

SILVA, F. B.; ARAÚJO, H. E.; SOUZA, A. L. O consumo cultural das famílias brasileiras. In: SILVEIRA, F. G. et al. (Org.). Gasto e consumo das famílias brasileiras contemporâneas, 2. Brasília: IPEA, 2007. p. 105-142. Disponível em: http://repositorio.ipea.gov.br/bitstream/11058/3253/2/Gasto\%20e\%20consumo\%20d as\%20fam\%C3\%ADlias\%20brasileiras\%20contempor\%C3\%A2neas\%20\%20v.\%202.pdf. Acesso em 2019.

SILVA, Marina Cabral da. "Para Que Serve a Literatura?"; Brasil Escola. Disponível em: https://brasilescola.uol.com.br/literatura/para-que-serve-a-literatura.htm. Acesso em 2019.

SILVA, Vera Maria Tietzmann. Literatura infantil brasileira: um guia para professores e promotores de leitura. 2. Ed. -ver.- Goiânia: Cânone Editorial, 2009.

SILVA, Solimar. Práticas de leitura: 150 ideias para despertar o interesse dos alunos - Petrópolis, RJ: Vozes, 2018.

SOARES, Magda Becker. As condições sociais da leitura: uma reflexão em contraponto. In:

ZILBERMAN, R.; SILVA, E. T. (orgs.). Leitura: Perspectivas interdisciplinares. São Paulo: Ática, 2000. 
TIBAU, Anderson... [et al.]; DAUSTER, Tania, FERREIRA, Lucelena (orgs.) - Por que ler? Perspectivas culturais do ensino da leitura. Rio de Janeiro: Lamparina, 2010.

YUNES, Eliana; OSWALD, M.L. (orgs.). A Experiência da Leitura. Edições Loyola, São Paulo, Brasil, 2003.

ZILBERMAN, R. (2008). O PAPEL DA LITERATURA NA ESCOLA. Via Atlântica, (14), 11-22. https://doi.org/10.11606/va.v0i14.50376. Acesso em 2019.

Enviado: Março, 2020.

Aprovado: Março, 2020. 